\title{
Is it Possible to Say Gastroesophageal Reflux Disease and Laryngopharyngeal Reflux are Different?
}

\author{
Ergun Sevil ${ }^{1 *}$, Togay Muderris ${ }^{2}$ and Muzaffer Kiris ${ }^{3}$ \\ ${ }^{1}$ Department of Otorhinolaryngology, Karaman State Hospital, Turkey \\ ${ }^{2}$ Department of Otorhinolaryngology, Bozyaka Training and Research Hospital, Turkey \\ ${ }^{3}$ Department of Otorhinolaryngology, Gulhane Training and Research Hospital, Turkey
}

Submission: June 11, 2018; Published: June 27, 2018

*Corresponding author: Ergun Sevil, Karaman State Hospital, Department of Otorhinolaryngology Head and Neck Surgery, 70000, Karaman, Turkey, Fax:903382263309, Tel: 905363104655; Email: drergunsevil@yahoo.com

\begin{abstract}
Objective: To find out the differences and similarities between these two diseases in the aspect of symptoms and findings.

Methods: We compared symptoms and laryngeal findings of 110 patients with laryngopharyngeal complaints and physical findings suggesting laryngopharyngeal reflux LPR (LPR group) and 86 patients who underwent esophagogastroscopy and diagnosed as lower esophageal sphincter (LES) incompetency and/or esophagitis (Gastroesophageal reflux disease (GERD) group).

Results: The most common complaints in LPR group were hoarseness in 98 (89\%) patients, chronic throat clearing in 96 (87.2\%) patients, sore throat in $92(83.9 \%)$ patients, globus in $82(74.5 \%)$ patients and dysphagia in $78(70.9 \%)$ patients. In GERD group, common complaints were hoarseness in $40(46.5 \%)$ patients, chronic throat clearing in $60(69.7 \%)$ patients, sore throat in 40 (46.5\%) patients, globus in 28 (32.5\%) patients and dysphagia in $24(27.9 \%)$ patients. In laryngoscopic examination; there was vocal cord hyperemia in 76 (69\%) patients, vocal cord edema in $76(69 \%)$ patients, diffuse laryngeal hyperemia in $12(10.9 \%)$ patients, vocal cord nodule in 10 (9\%) patients, vocal cord polyp in 12 $(10.9 \%)$ patients, interarytenoid hyperplasia (pachydermia) in $54(49 \%)$ patients in LPR group whereas there was vocal cord hyperemia in 40 (46.5\%) patients, vocal cord edema in 18 (20.9\%) patients, arytenoid hyperemia in 46 (53.4\%) patients, vocal cord nodule in 8 (9.3\%) patients, and pachydermia in $22(25.5 \%)$ patients in GERD group.
\end{abstract}

Conclusion: It is not possible to say that these two diseases depend on the same origin and encloses same symptoms and findings.

Keywords: Gastroesophageal Reflux; Laryngopharyngeal Reflux; Hoarseness; Esophagitis; Lower Esophageal Sphincter

\section{Introduction}

Gastroesophageal reflux refers to the regurgitation of gastric contents into the esophagus without forcing or vomiting. If these contents pass through the superior esophageal sphincter and reach to larynx or pharynx; it is described as laryngopharyngeal reflux (LPR) [1,2]. The most common symptoms associated with LPR are hoarseness, voice fatigue or break, frequent throat clearing, chronic cough, sore throat, globus sensation and postnasal drip [3]. Approximately the $4-10 \%$ of patients who are referred to ENT clinics has symptoms and complaints related to laryngopharyngeal reflux [4]. $60 \%$ of patients with chronic pharyngitis, chronic laryngitis and sore throat are related to reflux, but less than $50 \%$ of otolaryngologic patients with symptoms of laryngopharyngeal reflux have GERD symptoms like heartburn and regurgitation. Patients with severe complaints of GERD do not have to have LPR, and patients with LPR do not have to show gastroenterologic symptoms, despite of our expectations [1]. The question why some patients with reflux have only otorhinolaryngeal complaints while others mainly have typical gastroenterologic symptoms still remains to be answered. In this prospective study, we compared the symptoms and laryngeal findings of LPR patients and GERD patients to find out the possible relationship between these two distinct diseases in the aspect of symptoms and findings.

\section{Material and Methods}

This study was performed in the Otolaryngology and Gastroenterology Clinics between May 2013 - December 2015. Informed consent was obtained from all the patients. Approval for the study was granted by the local ethic committee (Ethics Committee Decision no: 2013/137). A group of 110 patients (36 male, 74 female, age range 14-73 years, mean 39.2 years) that attended to ENT outpatient clinic with laryngopharyngeal complaints and physical findings suggesting LPR formed the LPR 
group. Reflux symptom index (RSI) was used for determination of the symptom severity (Table 1) [5]. A complete head and neck examination together with videolaryngoscopy was performed and physical findings were scored according to the reflux finding score (RFS) (Table 2) [6]. Patients were accepted as LPR either if their RSI was higher than 13 [7] or RFS was higher than 7 [6]. Then the patients were referred to gastroenterology clinic for esophagogastroscopy. GERD group was consisted of 86 patients (62 male, 24 female, age range 16-74 years, mean 40.7 years) that were examined in gastroenterology clinic and diagnosed as GERD after performing esophagogastroscopy. Patients with complaints of heartburn and regurgitation were diagnosed as GERD if they had LES incompetency and esophagitis in endoscopy and biopsy. All patients that had the diagnosis of GERD were referred to ENT clinic for a detailed questioning and physical examination. The patients with GERD were included into the study if their RFS was lower than 7 and RSI was lower than 1 suggested that they do not have LPR.

\section{Table 1. Components of the reflux symptom index} Within the last month, how did the following problems affect you? $0=$ no problem $5=$ severe problem

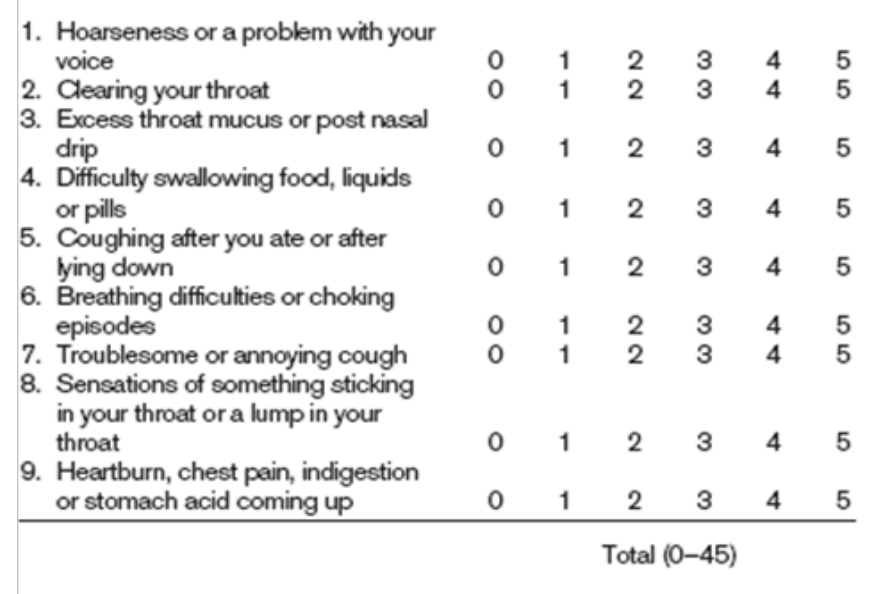

Table 2. Components of the reflux finding score

\begin{tabular}{|ll}
\hline Variable & Score, $p t$ \\
\hline Subglottic edema & Present $=2$ \\
Ventricular obliteration & Absent $=0$ \\
& Partial $=2$ \\
Erythema/hyperemia & Complete $=4$ \\
Vocal cord edema & Arytenoids only $=2$ \\
& Diffuse $=4$ \\
& Mild $=1$ \\
& Moderate $=2$ \\
Diffuse laryngeal edema & Severe $=3$ \\
& Polypoid $=4$ \\
& Mild $=1$ \\
Posterior commissure hypertrophy & Moderate $=2$ \\
& Severe $=3$ \\
& Obstructing $=4$ \\
Granuloma/granulation & Mild $=1$ \\
& Moderate $=2$ \\
Thick endolaryngeal mucus/other & Severe $=3$ \\
& Obstructing $=4$ \\
& Present $=2$ \\
& Absent $=0$ \\
\hline
\end{tabular}

Total $0-24$ points.
Both of the groups filled an information form about symptoms (Table 3) and another form is filled by physician that defines patient physical examination findings. Laryngeal examination was performed with 70 degree rigid laryngoscopy. Findings like hyperemia, edema, polyps, nodules, contact ulcers, granulomas and other mucosal disorders of vocal cord, hyperemia or edema at arytenoids, interarytenoid hyperemia and pachydermia laryngitis, diffuse laryngeal hyperemia or edema were also defined in the information form filled by physician. Patients with LPR symptoms and findings underwent esophagogastroscopy for evaluation of lower esophageal sphincter incompetency and esophagitis. Biopsies were taken for evaluation of the degree of esophagitis during esophagoscopy. All of the patients undergone a detailed ENT examination. Patients with a history of medical treatment for any kind of reflux or any medication during the study were excluded from the study. Patients with allergic rhinitis, asthma, chronic pharyngitis or sinusitis were also excluded. Mann-Whitney U test was used for comparison of nonparametric data. All statistical calculations were performed using commercially available software (SPSS for Windows, SPSS Inc, Chicago, Illinois).

Table 3: Symptoms asked in questionnaire.

\begin{tabular}{|c|}
\hline Hoarseness \\
\hline Sore throat \\
\hline Sensation of foreign body in throat (Globus) \\
\hline Dysphagia \\
\hline Odynophagia \\
\hline Chronic cough \\
\hline Postnasal dripping \\
\hline Regurgitation \\
\hline Heartburn \\
\hline Halitosis \\
\hline Taste disorders \\
\hline Neck pain \\
\hline Recurrent apthous stomatitis \\
\hline
\end{tabular}

Results

The most common subjective complaints in LPR group were hoarseness in 98 patients (89\%), chronic throat clearing in 96 patients $(87.2 \%)$, sensation of frequent swallowing in 96 patients $(87.2 \%)$, sore throat in 92 patients $(83.6 \%)$, globus in 82 patients $(74.5 \%)$, dysphagia in 78 patients $(70.9 \%)$, odynophagia in 58 patients $(52.7 \%)$ frequent cough in 50 patients $(45.4 \%)$, regurgitation in 84 patients (85.4\%) and heartburn in 84 patients $(85.4 \%)$. The most common subjective complaints in GERD group were hoarseness in 40 patients (46.5\%), chronic throat clearing in 60 patients $(69.7 \%)$, sensation of frequent swallowing in 58 patients $(67.4 \%)$ sore throat in 36 patients (41.8\%), globus in 24 patients (27.9\%), dysphagia in 24 patients (27.9\%), odynophagia in 18 patients $(20.9 \%)$, frequent cough in 46 patients $(53.4 \%)$, regurgitation in 60 patients $(69.7 \%)$ 


\section{Global Journal of Otolaryngology}

and heartburn in 66 patients (76.7\%) (Table 4). Between these two groups all symptoms were seen more in the LPR group except chronic cough and postnasal drip, and the difference was statistically significant $(\mathrm{p}<0.05)$. According to laryngoscopic examination, in LPR group; 76 patients (69\%) had vocal cord hyperemia, 36 patients $(32.7 \%)$ had edema at vocal cords, 68 patients $(61.8 \%)$ had arytenoid hyperemia, 50 patients $(45.4 \%)$

Table 4: Comparison of symptoms. had edema at arytenoids, 12 patients (10.9\%) had diffuse laryngeal hyperemia, 6 patients $(5.4 \%)$ had reinke edema, 10 patients (9\%) had vocal cord nodule, 12 patients $(10.9 \%)$ had vocal cord polyp, 2 patient (1.8\%) had interarytenoid polyp and 54 patients (49\%) had interarytenoid hyperplasia (pachydermia).

\begin{tabular}{|c|c|c|c|c|}
\hline \multicolumn{3}{|c|}{ LPR Group } & \multicolumn{2}{|c|}{ GERD Group } \\
\hline \multicolumn{3}{|c|}{$n=110$} & \multicolumn{2}{|c|}{$\mathrm{n}=86$} \\
\hline & $\mathbf{N}$ & $\%$ & $\mathbf{n}$ & $\%$ \\
\hline Hoarseness & 98 & 89 & 40 & 46.5 \\
\hline SoreThroat & 92 & 83.6 & 40 & 46.5 \\
\hline ChronicThroatCleaning & 96 & 87.2 & 60 & 69.7 \\
\hline Globus & 82 & 74.5 & 28 & 32.5 \\
\hline Dysphagia & 78 & 70.9 & 24 & 27.9 \\
\hline Odyno & 58 & 52.7 & 18 & 20.9 \\
\hline Chroniccough & 50 & 45.4 & 46 & 53.4 \\
\hline Postnasaldripping & 66 & 60 & 42 & 48.8 \\
\hline Regurgitation & 84 & 85.4 & 60 & 69.7 \\
\hline Heartburn & 84 & 85.4 & 66 & 76.7 \\
\hline Halitosis & 5449 & & 48 & 55.8 \\
\hline Tastedisorders & 60 & 54.5 & 32 & 37.2 \\
\hline Neckpain & 60 & 54.5 & 38 & 44.1 \\
\hline
\end{tabular}

The laryngoscopic findings in GERD group were vocal cord hyperemia in 40 patients (46.5\%), vocal cord edema in 46 patients (53.4\%), arytenoid hyperemia in 46 patients (53.4\%), arytenoid edema in 24 patients (27.9\%), diffuse laryngeal hyperemia in 8 patients (9.3\%), vocal cord nodule in 8 patients (9.3\%), interarytenoid hyperplasia (pachydermia) in 22 patients (25.5\%) (Table 5). Between these two groups, vocal cord hyperemia and pachydermia were more common in LPR, and the difference was statistically significant $(p<0,05)$. Other laryngeal

Table 5: Comparison of laryngeal findings. findings were not significantly different. In the endoscopic examination and biopsy, we found that, in LPR group, 78 (70.9\%) patients had LES incompetency and 50 (45.5\%) patients had esophagitis. The presence or the anamnesis of oral aphthous lesions was only seen in 40 (36.3\%) patients in LPR group and in $18(20,9 \%)$ patients in GERD group. Dental cavities were seen in $74(67.2 \%)$ in LPR and $62(72 \%)$ in GERD group. The difference of these findings was not statistically significant ( $p>0.05$ ).

\begin{tabular}{|c|c|c|c|c|}
\hline \multicolumn{3}{|c|}{ LPR Group } & \multicolumn{2}{|c|}{ GERD Group } \\
\hline & $\mathbf{n}$ & $\%$ & $\mathbf{n}$ & $\%$ \\
\hline Vocal cord hyperemia & 38 & 69 & 20 & 46.5 \\
\hline Vocal cord edema & 18 & 32.7 & 9 & 20.9 \\
\hline Arytenoid hyperemia & 34 & 61.8 & 23 & 53.4 \\
\hline Arytenoid edema & 25 & 45.4 & 12 & 27.9 \\
\hline Diffuse laryngeal edema & - & - & - & - \\
\hline Diffuse laryngeal hyperemia & 6 & 10.9 & 4 & 9.3 \\
\hline Subglottic edema & - & - & - & - \\
\hline Contact ulcer & 3 & 5.4 & - & - \\
\hline Reinke edema & 3 & 5.4 & - & - \\
\hline Vocal cord nodule & 5 & 9 & 4 & 9.3 \\
\hline Vocal cord polyps & 6 & 10.9 & - & - \\
\hline
\end{tabular}




\section{Global Journal of Otolaryngology}

\begin{tabular}{|c|c|c|c|c|}
\hline Mucosal disorders & 16 & 29 & 9 & 20.9 \\
\hline Pachydermia & 27 & 49 & 11 & 25.5 \\
\hline Granuloma & 2 & 3.6 & 1 & 2.3 \\
\hline
\end{tabular}

\section{Discussion}

There are too many patients with complaints and findings of reflux in daily practice of ENT and gastroenterology clinics. Despite the similarity of the mechanism, gastric component reflux to esophagus, LPR and GERD usually don't have same symptoms and findings. Lower esophageal sphincter is an important barrier for reflux. Herein, we found $72(65,4 \%)$ patients have LES incompetency in LPR group according to their esophagoscopy. This is a clear evidence that most, but not all of the LPR patients have LES pathology. Many studies showed that heartburn is also a major symptom of LPR and exists in many LPR patients. Ylitalo et al. found that regurgitation and heartburn was seen $63 \%$ of $80 \mathrm{LPR}$ patients [8]. In our study, we found that $85,4 \%$ of LPR patients have this complaint.

Most of LPR patients refer to an ENT clinic with a complaint of vocal disorder, especially hoarseness. Furthermore, some investigations have demonstrated that LPR had a part in the pathogenesis of chronic rhinosinusitis, middle ear effusion, postnasal drip, halitosis, smelling and tasting problems. Koufman et al. $[9,10]$ found that $88 \%$ of 113 reflux patients had hoarseness [11]. Ylitalo et al. [8] found hoarseness in $63 \%$. Our results were similar to those; we found hoarseness in $89 \%$ of LPR patients. In GERD group hoarseness was seen only in $46,5 \%$ of patients. The difference was statistically significant between these two groups $(p=0,001)$. These finding suggests that hoarseness is a valuable symptom in diagnosis of LPR. Globus sensation may be seen in esophagitis, esophageal motility disorders, esophageal stickness and irritation of laryngeal structures. Chen et al. study found no evidence of reflux in globus patients based on ambulatory $\mathrm{pH}$ monitoring [12]. Despite this gastroesophageal reflux (GER) has been suggested to be a major etiology of this symptom, potentially accounting for $23 \%-68 \%$ of globus patients [13].

We found this ratio as $74,5 \%$ in LPR group and $32,5 \%$ in GERD group. Between LPR and GERD patients the difference was statistically significant $(p=0,001)$. Morrison et al. [14]. Who described the irritable larynx syndrome, insist that more than 90 percent of this disease depends on reflux. It was seen that laryngospasm which was triggered by reflux attacks resolved after antireflux therapy. According to our study, 54,5\% of LPR patients and $39,5 \%$ of GERD patients described laryngospasm attacks, the difference between groups was not significant $(p=0,09)$. One of the leading symptoms in both groups was cough. We found chronic cough in $45,4 \%$ of LPR group and in $53,4 \%$ of GERD group. These findings are correlated to the literature. Between two groups there was no significant difference $(p=0,409)$. The edema of posterior comissure and interarytenoid hyperplasia is called as pachydermia, and usually is seen in advanced stages of LPR. According to Fraser et al pachydermia is not a confident finding when diagnosing LPR [15]. In our study, the difference was statistically significant between the groups regarding pachydermia ( $\mathrm{p}=0.04)$. We found the symptoms like hoarseness, chronic throat cleaning, and sensation of foreign body in throat, laryngospasm attacks dominantly in LPR patients. Vocal cord hyperemia, posterior laryngitis and pachydermia were also found dominantly in LPR group, and it seems that these findings are valuable in diagnosis of LPR especially in the absence of $\mathrm{pH}$ monitoring.

\section{Conclusion}

In conclusion, it is not possible to say that these two diseases depend on the same origin and encloses same symptoms and findings. Laryngeal symptoms and findings were also seen commonly in GERD. Because of that, when managing LPR patients who are diagnosed only on the basis of symptoms or findings, it is important to keep in mind that these patients could also have GERD. Generally typical symptoms and physical examination findings are adequate for initiation of empirical therapy, but we think ambulatory 24- hour $\mathrm{pH}$ monitoring, esophagoscopy and if necessary esophageal biopsy must be performed for differentiation of these diseases and proper treatment.

\section{References}

1. Koufman JA (2002) Laryngopharyngeal reflux is differrent from classic gastroesophageal reflux disease. Ear Nose \& Throat J 81(9 suppl 2): $7-9$

2. Ossakow SJ, Ella G, Colturi T, Bogdasarian R, Nostrant TT (1987) Esophageal reflux and dysmotility as the basis for persistent cervical symptoms. Ann Otol Rhinol Laryngol 96(4): 387-392.

3. Toohill RJ, Kulin JC (1997) Role of reflux acid in pathogenesis of laryngeal disorders Am J Med 103(5A): 100-106.

4. Koufman JA, Wiener GJ, Wallace CW, Castell DO (1988) Reflux laryngitis and its sequelae: The diagnostic role of ambulatory 24-hour pH monitoring. J Voice 2(1): 78-89.

5. Belafsky PC, Postma GN, Koufmann JA (2001) Laryngopharyngeal reflux symptoms improve before changes in physical findings. Laryngoscope 111(6): 979-981.

6. Belafsky PC, Postma GN, Koufman JA (2002) The validity and reliability of the reflux symptom index (RSI). J Voice 16(2): 274-277.

7. Beaver ME, Stasney RC, Weitzel E, Stewart MG, Donovan TD, et al (2003) Diagnosis of laryngopharyngeal reflux disease with digital imaging. Otolaryngol Head Neck Surg 128(1): 103-108.

8. Ylitalo R, Lindestad PA, Ramel S (2001) Symptoms, laryngeal findings, and 24-hour $\mathrm{pH}$ monitoring in patients with suspected gastroesophagopharyngeal reflux. Laryngoscope 111(10): 1735-1741.

9. Ciorba A, Bianchini C, Zuolo M, Feo CV (2015) Upper aerodigestive tract disorders and gastro-oesophageal reflux disease. World J Clin Cases 3(2): 102-111.

10. Altundag A, Cayonu M, Salihoglu M (2016) Laryngopharyngeal reflux has negative effects on taste and smell functions. Otolaryngol Head Neck Surg 155(1): 117-121. 
11. Koufman JA, Amin MR, Panetti M (2000) Prevalance of reflux in 113 consecutive patients with laryngeal and voice disorders. Otolaryngol Head Neck Surge 123(4): 385-388.

12. S Kortequee, PD Karkos, H Atkinson, N Sethi, DC Sylvester, et al. (2013) Management of Globus Pharyngeus. International Journal of Otolaryngology 2013: 5.

13. Bong Eun Lee, Gwang Ha Kim (2012) Globus pharyngeus: A review of its etiology, diagnosis and treatment. World J Gastroenterol 18(20): 2462-2471.

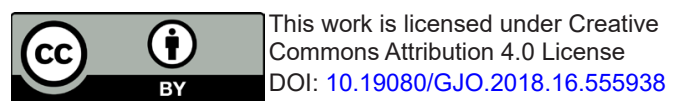

14. Smit CF, van Leeuwen JA, Mathus-Vliegen LM, Devriese PP, Semin A, et al. (2000) Gastropharyngeal and gastroesophageal reflux in globus and hoarseness. Arch Otolaryngol Head Neck Surg 126: 827-830.

15. Fraser AG, Morton RP, Gillibrand J (2000) Presumed laryngopharyngeal reflux: investigate or treat? J Laryngol Otol 114(6): 441-447.

\section{Your next submission with Juniper Publishers will reach you the below assets}

- Quality Editorial service

- Swift Peer Review

- Reprints availability

- E-prints Service

- Manuscript Podcast for convenient understanding

- Global attainment for your research

- Manuscript accessibility in different formats

( Pdf, E-pub, Full Text, Audio)

- Unceasing customer service

Track the below URL for one-step submission https://juniperpublishers.com/online-submission.php 